\title{
Investment, Training, Employment and Poverty Alleviation in Africa: A Critical Analysis
}

\author{
Wilfred A. Ndongko ${ }^{1}$ Ismaila Amadu ${ }^{2 *}$ \\ 1.Cameroon Academy of Sciences, Yaounde, Cameroon \\ 2.National Committee for the Development of Technologies, Ministry of Scientific Research and Innovation, \\ Yaounde, Cameroon \\ P.O. BOX 1457 Yaounde, Cameroon
}

\begin{abstract}
Today, it is overwhelmingly accepted that investing in training opens a large gate for the trained people for better jobs, high incomes, and improved living standards. It is in this regard that this paper endeavors to analyse the fundamental relationship between investment, training, employment and poverty alleviation in Africa. From the analyses, it has been noticed that the relationship between these factors is weak. Also, the latter are less integrated on the African continent, mainly due to inadequate investment in training required to trigger, strengthen, and sustain their integration. In addition, training and education are more theoretical and less adapted to the development needs of many African countries. To this effect, it is recommended that: first, the development programs on the continent should match the socio-economic needs of its people; second, more emphasis should be laid on providing quality, affordable and accessible technical and vocational training to the masses; lastly, the study and mastery of science, technology and innovation at all levels of education and training should be initiated, reinforced and/or enhanced by African governments.
\end{abstract}

Keywords: Investment, Training, Employment, Poverty Alleviation, Africa

DOI: $10.7176 / \mathrm{DCS} / 10-3-06$

Publication date:March $31^{\text {st }} 2020$

\section{Introduction}

Today, there is overwhelming evidence that unemployment and poverty are unacceptably high in Africa. Most school-leavers are unable to find decent and well remunerating jobs, living standards are declining. Moreover, crime rates, plight of diseases and socio-political conflicts, terrorism, emigration and rural-urban exodus, and so on are increasing rapidly in Africa. For example, there are about 12 million graduates coming on the job market every year on the continent (African Development Bank, 2018). Additionally, half of the world's poor and vulnerable people are harbored in Africa, with the vast majority of them living in densely populated countries such as Nigeria, Tanzania, Ethiopia, and Democratic Republic of Congo.

For the past two decades, initiatives notably the Millennium Development Goals (MDG) have been undertaken at the global scale to resolve the above crises affecting many countries, particularly those in Africa. As a result of the limited success of the MDGs in most developing economies, the Sustainable Development Goals (SDGs) were put in place with core objectives being climate change mitigation, the fight against poverty and the enhancement of sustainable and inclusive economic development and prosperity.

Most importantly, skills development was placed at the center of the global crusade against poverty, notably through the improvement of education and training, by making them more accessible and affordable, especially in the developing countries where the prevalence of poverty and its negative socio-economic impacts are relatively high. It is for this reason that registration for primary education in most countries is free.

In fact, training is a key element in harnessing and spurring sustainable and inclusive economic growth and development through the improvements in human capital, and the creativity and productivity of workforce. However, the positive spillover effects of the training of people on the society might not be felt by the masses if it is not of good quality and adapted to the needs of the society, region, or country (International Labor OrganizationILO, 2005b).

It is worth mentioning that the reform efforts of the past couple of decades and the attainment of the High Indebted and Poor Countries Initiative in 2006 enabled African countries to improve their macro-economic environments in the last decade. However, economic growth has not translated into substantial job creation and poverty reduction, considering that about half of the world's poor are on the African continent.

A critical element of economic growth which was not directly addressed during the reform era is investment, particularly in the education and training sector. Indeed, the reform programs adopted in most African countries have been widely noted as amounting to "adjustment by contraction". This consisted of downsizing the public sector wages and cutting back on public investment expenditure.

It is now widely acknowledged that if poverty is to be curbed significantly, the challenge of training and job creation has to be properly addressed. This is because employment could constitute the most sustainable way for alleviating poverty, especially when it is the poor and vulnerable people that are employed. It is therefore essential 
that the fundamental relationship between investment, training, employment and poverty alleviation be probed. To ignore this key relationship would amount to risking promoting inclusive and sustainable economic growth and development in the medium to long-term.

\section{Conceptual Framework}

For the purpose of this study, the key words investment, training, employment and poverty are defined as follows:

Investment refers to expenditure made by economic agents for the production of goods and services in order to satisfy the needs of people. Investments made by the public sector are for the satisfaction of the general interest or needs of the population, meanwhile those made by the private enterprises and households are to maximize profits.

Training on its part means the act of providing learners with knowledge, aptitudes, abilities, capacities and skills by instruction and practice that would enable to them to adequately, correctly and effectively do a particular job or task. Therefore, training would vary according to the nature and requirement of the available and future jobs, as well as the national and global macroeconomic environments.

Employment is the relationship between an employer and an employee materialized by a work contract, which specifies the numbers working hours, wage, task to be done, etc. In this regard, an individual is said to be employed if he/she does a particular job for at least an hour per week for a given wage rate. In this study, employment takes into account the decency of the job and the remuneration of doing it.

Poverty could be defined as the incapacity of an individual to satisfy his/her basic needs like nutrition, healthcare, transportation, clothing, education, housing, etc., as well as those of the people (family) depending on $\mathrm{him} /$ her for their livelihood due to extremely limited or lack of material and financial resources. Poverty, therefore, could be lack of monetary or non-monetary means to live a decent life. It is monetary when the daily income of an individual is below USD 1.9 (the so called poverty line) and non-monetary when an individual does not have physical assets like cars, houses, and land that could be transformed into liquid assets.

The relationship between investment, training, employment and poverty alleviation is illustrated in the following flow diagram.

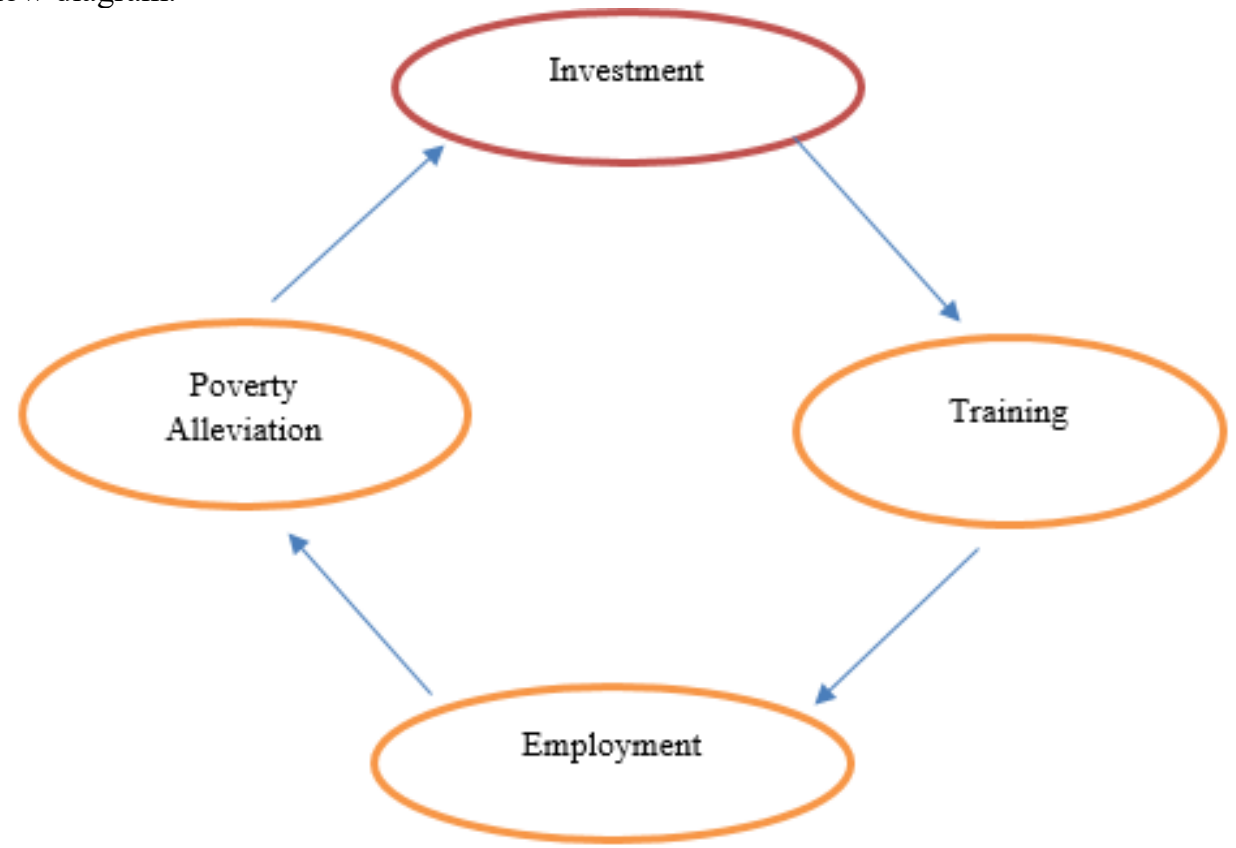

Figure 1: The Flow Diagram Explaining the Links Between Investment, Training, Employment and Poverty Alleviation

Although strenuous efforts have been made to upgrade the level and quality of training in Africa during the immediate post-independence era, it has become clear that Africa lost the momentum it gathered in the educational race during the late 1980s and 1990s, principally because of the implementation of the Structural Adjustment Programs imposed on it by the International Monetary Fund and the World Bank. Consequently, the quality of educational and training infrastructure dilapidated, recruitments in the sector suspended, salaries of teachers significantly slashed, etc.

Thus, the quality of education and training drastically deteriorated and the number of illiterates and people with low skills considerably increased on the continent. For example, according to the World Bank (2014b), the African region generated about one million illiterates every year, which is adding on to the estimated 142 million illiterates with little or no skills that Africa harbored in the year 2000. Comparatively, there were about 9 million 
illiterates in the West, in 2000. Since then, the number of illiterates reduces by one million on a yearly basis.

These high numbers of illiterates and unskilled people accumulated by African countries is partly because of their limited financial resources that could enable them to significantly improve the infrastructure of education and training institutions, recruit and train teachers, etc. For instance, estimates by the African Development Bank (2018) reveal that the continent's infrastructure needs, including education and training vary between 130 and 170 USD billion a year. But, the present financial capacity of the continent is less than 100 USD billion, thereby creating a financial gap in infrastructure funding which ranges between 68 and 108 USD billion.

Although there are very limited resources available to enable substantial investment in training in Africa, it is clear that investing adequately in the education and training of people is critical for a countries socio-economic development. This is because an educated or a well trained workforce tends to have higher productivity than one which is poorly educated and with limited skills (Omoniyi, 2013). For example, in Nepal, it was found that the completion of at least seven years of schooling increased the productivity of rice farmers by 13 per cent. As such, their incomes could also increase, and eventually reduce poverty (Jamison and Moock, 2004). To this effect, investment in the training of people stimulates productivity and increases incomes, thereby reducing poverty.

In the developed countries, it is partly because of the high literacy rates and significant number of skilled labor that have enabled them to improve their production, create more decent and remunerating jobs, and substantially increase the incomes of people, and eventually reduce poverty considerably (Joe, 1986). Even though training alone cannot transform an economy, it contributes significantly by improving the productivity, efficiency and effectiveness of a workforce through the acquisition of skills. These skills enable people to be more creative and innovative, to be more productive and to easily get decent and well remunerating jobs, or create their own businesses and employ other people. In this regard, adequately and properly investing in the training of people could be considered as a catalyst that increases productivity, employment, and incomes.

However, employment can significantly contribute in reducing poverty if enterprises invest in labor intensive sectors and the wages paid to their employees be substantial enough to enable them and their dependents to live decently or comfortably. For example, investments in the educational and training industry itself would certainly absorb more labor and reduce poverty on an unprecedented scale considering that it is a highly labor intensive sector.

Investing in training opens a large gate for the trained people for better jobs and high incomes. However, for investments in education and training to provide the citizens of a country with the necessary skills to enable them to be highly productive and get well remunerating and decent jobs, the training should be mainly technical and vocational and should equally be affordable, accessible, adequate and adapted to the needs of the economy (Paul and Jan, 1999).

The availability of a significant number of skilled labor in a country attracts multinational corporations whose choice of a location to a large extent depends on a skilled workforce. The entry of foreign corporations in a country would generate direct and indirect employment that would increase the incomes of the employed and thereafter alleviate poverty in the country. Moreover, Foreign Direct Investment (FDI) brings in new technologies, innovations, and production techniques, as well as better managerial methods with a strong potential to boost the production of domestic firms through spillover effects.

Furthermore, the improvement in the skills and incomes of people as well as their demand for consumer goods and services attract new firms wanting to take advantage of the skilled labor to maximize their profits. As such, the creation and entry of new enterprises in a country will increase, and eventually employment will rise, incomes of new employees will improve. As such, the savings of households and their access to bank services will equally improve. This could result to increase borrowing by enterprises to invest, and subsequently improve their production, efficiency and competiveness. This would therefore form a circle that would harness and enhance sustainable and inclusive economic growth and development that are badly needed in Africa for its millions of poor and vulnerable people.

For instance, only about 40 per cent of Ugandans and 54 per cent of Tanzanians were financially included in 2016. Additionally, in Sub Saharan Africa, about 350 million adults do not have bank accounts. As a result, commercial banks which are mainly the subsidiaries of multinational banks tend to limit the quantity of money they give out in the form of loans.

Moreover, the few loans the commercial bank grant to their customers are mainly limited in the short-term. Consequently, the financial intermediation of commercial banks in developing African economies and its impact on increasing investments and consumption are very insignificant. In order to remedy this, African governments should encourage and facilitate to their citizens the possession of banks to enable them to save in financial institutions, and reduce the tesorisation of money (African Development Bank, 2013).

Worse still, most of the FDI flowing to Africa goes to the sourcing sector which is capital intensive and thus creates fewer jobs. Also, the extracted natural resources like gold, iron, cobalt, etc. are not transformed locally, but exported to developed countries at low and fluctuating prices that are fixed by the buyers. As a result, there are high economic growth rates in many African countries like Nigeria, but still the prevalence rate of poverty is very 
high. This has resulted to a limited development of value chains in Africa that could generate substantial numbers of jobs, create abundant wealth, boost inclusive economic growth and alleviate poverty on the continent.

To this effect, there are about 12 million fresh job seekers every year who come knocking on the job market for employment. Partly because of this reason, since the 1990s, it is estimated that in Sub Saharan Africa, a percentage growth in Gross Domestic Product (GDP) reduces poverty by about 0.7 per cent. However, for the rest of the world, excluding China, a percentage increase in GDP leads to a 2 per cent reduction in poverty. This difference is accounted for by the strong links between the various sectors of the economies of the emerging and developing countries, and the location and nature of investments that drive economic growth in the countries.

Furthermore, in Africa, between 2000 and 2008, employment rates increased at an annual average of 2.8 per cent. This percentage is about half the rate of economic growth observed on the continent during that period. However, between 2009 and 2014, the annual average employment growth rates on the continent increased to about 3.1 per cent. Nonetheless, this high employment growth rate observed at the period was higher than that seen between 2000 and 2008. But still yet, it is lower than the average economic growth of the continent by about 1.4 points.

This suggests that although the economic growth rates observed on the continent are improving, they are not strong, sustainable and inclusive enough to create a significant number of jobs that would enable Africans to improve their incomes and get out of poverty. This slow and limited job growth is mainly affecting women and youth (aged between 15 and 24) who constitute the bulk of the unemployed, underemployed and the poor and vulnerable proportion of the population.

In 2005, it was estimated that Africa had about 226 million youth, and this number of the youth is projected to increase to 321 million by 2030 . Thus, there is an urgent need to give them adequate technical and vocational training that would enable to develop skills, which they would use to create and innovate, improve their productivity, get decent jobs, ameliorate their livelihoods and contribute significantly in boosting the socioeconomic development the continent. If the training of the youth is poor, their chances of obtaining skills will be compromized, and the technological and industrial development of the continent will equally be threatened. As such, many people will be confined to agricultural activities with insignificant incomes that would trap them in poverty for decades, with a possibility of increasing crime rates, terrorism, emigration, etc.

In Africa and most other developing countries, economic growth is driven by agricultural and sourcing activities that generate relatively less number of decent jobs (ILO, 2005). For example, in the past decade, African countries, notably Nigeria and Angola were among the top ten fastest growing economies in the world. In Nigeria, for example, the oil sector accounts for over 80 per cent of the Nigerian GDP.

Thus, the continent's economic growth rates are principally determined by capital intensive activities like mining that generate fewer jobs and have relatively weaker impact on the incomes and living standards of the masses. Labor intensive activities, particularly in the industrial and service sectors, on their part generate a significant number of decent and well remunerating jobs. To this effect, they are regarded as key factors needed to transform an economy from the state of a developing to a developed country. In this light, the industrial and service sectors are regarded as an anti-dote for poverty and suitable catalyst for sustainable and inclusive economic growth and development.

\section{Africa's Economic Performance and Poverty}

Some of the interesting trends of Africa's socio-economic performance include the fact that:

The average growth rate of GDP per capita declined into negative range since the 1980's and during the first few years of the 1990s. However, in recent years, economic growth rates in Africa have been improving progressively. For example, the real output growth in Africa increased 2.2 per cent in 2016, 3.6 per cent in 2017 and 4.1 per cent in 2018. As a result, the per capita income in Sub-Saharan Africa, excluding Nigeria, increased by 1.1 per cent in 2017 (African Development Bank, 2018). Moreover, it was projected to increase by 1.5 per cent in 2018 and 1.8 per cent in 2019. It could be noted that the improvements in the per capita income is low and consequently not adequate to considerably reduce poverty and substantially improve living standards in the region;

Over the last decade in Africa, that is, between 2006 and 2016, tax revenues increased in absolute terms by about 2.3 per cent. The continent now collects about 500 USD billion in tax revenue every year, 50 USD billion in foreign aid, 60 USD billion in remittances, and 60 USD billion in FDI inflows;

Despite the recent improvements in Africa's economic growth rates compared to the late 1980s and early 1990s, it accounts for less than 5 per cent of trade in goods and services at the international stage, and about 2 per cent of global exports in merchandise.

Although, since 1990, extreme poverty has been decreasing across the globe, about 50 per cent of Africa's population still lives below the extreme poverty line of the 1 USD per day. In most of Sub Saharan African countries, the proportion of the population living below the extreme poverty line is similar across the continent with an average ranging between 39 and 46 per cent of the population. In Cameroon for example, about 40 per cent of the people live in extreme poverty. Comparatively, the proportion of people living in extreme poverty in 
Central Africa is about 2.5 times higher than that in South Asia and 4.6 times that of Latin American and Caribbean countries (World Bank, 2014b);

Employment rates in African countries increased by an annual average of 2.8 per cent between 2000 and 2008 . However, only Algeria, Burundi, Botswana, Cameroon, and Morocco experienced employment growth rates above 4 per cent. Furthermore, annual employment growth increased to an average of 3.1 per cent between 2009 and 2014 despite slower economic growth. Nonetheless, this rate was lower than average economic growth rate by 1.4 per cent.

The limited and inadequate creation of decent and well remunerating growth in Africa have significantly retarded poverty reduction. For example, the proportion of the people living in poverty declined from 56 per cent in 1990 to 43 per cent in 2012. As a result, today, about half of the world's poor live in Africa, particularly in the rural areas;

It is projected that Africa will be the youngest and most populous continent in the next few decades. To this effect, its labor force is estimated to increase from 620 million in 2013 to approximately 2 billion in 2063 (African Development Bank, 2018). Therefore, the continent has to privilege economic growth paths that would substantially absorb this large pool of estimated labor force, otherwise, the continent would become an ocean harboring unemployment, high crime rates, terrorism, etc.

\section{Conclusion and Policy Implications}

An attempt has been made to show the fundamental relationship existing between investment, training, employment and poverty in the African context. The following key issues and the related policy implications can be highlighted:

First, Africa's economic growth and performance have been improving in the past few years, although there are high disparities in economic growth, competitiveness and resilience among the countries. Also, the structural transformation of the continent has remained relatively slow compared to that of other developing countries like those of Latin America and Asia. In this regard, it is recommended that African countries boost their economic growth rates by investing more in sectors like manufacturing with high multiplier effects;

Second, the source and pattern of the growth process are key determinants of employment outcomes. Therefore, investment, education and training, and development programs of each African country have to match the socio-economic needs of its people;

Third, to employment contents and in particular, Africa's rural and agricultural development constitutes the key to poverty reduction through the production of high quality food available for and accessible to the masses, the creation of employment, exports, etc. To this effect, the transformation of the agricultural and primary products with emphasis to create value chains could lift out many people out of poverty, reduce hunger and starvation, and malnutrition, boost economic growth, diversify exports, and enhance socio-economic development in Africa (Robert and Jong, 1993);

Fourth, Africa's investments, especially in large-scale industrial ventures are consistently employment inelastic. Hence, there is the need to refocus attention on investing in the micro and small enterprises for enhanced employment impact at the base for the poor, vulnerable and under privileged who need it the most;

Fifth, public and private sector investments have to be complementary with the former having the potentials to trigger the latter. This with the priority to improve business environment by building Africa's dilapidated infrastructural facilities, reducing corruption, improving security, etc.;

Sixth, available evidence points to a growing crisis of financial intermediation in many African countries. Moral hazard and adverse selection arising from information asymmetry are among the factors implicated in this phenomenon. Efforts to penetrate the rural and the informal sectors with innovative financial services based on country specific profiles are needed. Institutionalizing credit information services would also facilitate lending by reducing the risks;

Seventh, considering Africa's technical and vocational training laggardness, an accelerated investment in training (in quantitative and qualitative), increasing its accessibility and affordability, and adapting the curricular to the development needs of the continent are highly required for underpinning efforts in investment promotion for long-term poverty alleviation. This would eventually unlock the potentials of Africans to enable them to significantly participate and contribute in the socio-economic development of their continent (ILO, 1997). Nonetheless, improving education should be accompanied by improvements in the health situations of the people. When a country has a significant number of a healthy and skilled workforce, then it can easily create, innovate, produce quality products at a large-scale, and eventually reduce poverty substantially (Felix, 2001);

Eighth, African countries should improve their business environment to enable their industries to thrive. This could also attract more labor and capital intensive FDI that would increase employment and incomes and also improve the livelihood of the people employed as well as that of those who depend on them for a living (wives, children, parents, etc.);

Ninth, the modernization of Africa's agriculture and the improvement and development of its labor intensive 
industries could create more jobs, improve the incomes of Africans, substantially reduce poverty, enhance production, diversify and increase exports, gain more foreign revenues, and eventually achieve high, inclusive and sustainable socio-economic growth and development. As such, Africa could generate decent and well remunerating jobs for its 12 million young people who come to the labor market in search of jobs every year;

Tenth, experience shows that piecemeal and uncoordinated efforts in Africa to promote investment and to yield the expected synergy for sustained growth with substantial employment gains and poverty reduction have a limited positive impact on poverty alleviation, and socio-economic development of the continent as exemplified by the high rates of poverty and unemployment among its people. This lesson underscores the need to adopt a twopronged coordinated strategy in order to achieve high, inclusive and sustainable economic growth and development in Africa;

Last, at the level of policy structure, the macro-economic stabilization efforts to mainstream employment considerations need to be linked to the sectoral and micro policies to achieve policy coherence. At the level of the key stakeholders (government, private sector and civil society), there should be a critical complementarity of roles for generating and sustaining the required investment synergy.

\section{References}

African Development Bank (2018). African Economic Outlook, 2018 Edition.

African Development Bank (2013). Financial Inclusion in Africa, 2013 Edition.

Felix, F, N. (2001). Employment and Economic Growth in Cote d'Ivoire: Analysis of Structural Determinants. African Economic Review. Vol. 13, No.1.

International Labor Organization (2005). Training for Rural Economic Empowerment (TREE). Expanding Economic Opportunity and Income Security Through Workforce Education, Skills Training, Employment Creation and Economic Development in Pakistan and Philippines, Fifth Technical Report. Geneva.

International Labor Organization (2005b). Vocational Training and Skills Development in the Poverty Reduction Strategy Papers: A Preliminary Review Skills and Employability Department, Geneva.

International Labor Organization (1997). Jobs for Africa: A Policy Framework for Employment Intensive Growth Strategy. Geneva, 1997. pp. 33-37.

Jamison, D. and Moock, P. (2004). Farmer Education and Farmer Efficiency in the Nepal: The Role of Schooling. World Development 42 (3), 205-218.

Joe, U, U. (1986). Education Employment Connection: The Nigerian Experience. Artha-Vikas Journal of Economic Development. Vol. XXII.

Omoniyi, M, B, I. (2013). The Role of Education in Alleviating Poverty and Economic Development: A Theoretical Perspective and Counselling Implications. British Journal of Arts and Social Sciences Vol.15, No II.

Paul, C., and Jan, G. (1999). Explaining African Economic Performance. Journal of Economic Literature, Vol. 37, March, 1999, pp.61-111.

Robert B., and Jong, W, L, C. (1993). Losers and Winners in Economic Growth. Proceedings of the World Bank Annual Conference on Development Economics pp. 267-97.

World Bank (2014b). World Development Indicators. Washington, D.C. The World Bank. Retrieved from http://data.worldbank.org/data-catalog/world-development-indicators. 